\title{
Isolated Follicle Stimulating Hormone Deficiency
}

National Cancer Institute

\section{Source}

National Cancer Institute. Isolated Follicle Stimulating Hormone Deficiency. NCI

Thesaurus. Code C121142.

Subnormal concentration of follicle stimulating hormone (FSH), associated with mutations in the FSHB gene, encoding follitropin subunit beta. 